\title{
FIRST STRUGGLES OF THE EMERGING DISTANCE LEARNING NECESITY IN ROMANIAN EDUCATIONAL SYSTEM IN THE CONTEXT OF COVID-19
}

\author{
Irina-Miruna RADU \\ Bucharest University of Economic Studies, Bucharest, Romania \\ miruna.radu@outlook.com
}

\begin{abstract}
Context: The social context of COVID-19 forced everyone to social distancing. This had an impact on the way people way of living. The education system is no exception. The main "actors" were put in a challenging situation. They were faced with implementing distance learning in an environment that has not been fully prepared for this. Objectives: This paper proposes to investigate the primary education's "actors" (inspectors, teachers, parents) opinions regarding the Romanian educational system and identify the struggles they faced in the beginning of Covid-19 context.

Method: This article uses an analysis of the comments on subjects regarding the transition from the classroom to home, published on platforms related to education to portrait better the context and struggles of implementing online learning in a system not fully prepared.

Results: As a result, the paper highlights the struggles of implementing distance learning for primary schools at this moment.

Conclusion: This paper highlights the challenges that must be overcome to have an educational system that can support distance learning for young children.
\end{abstract}

Keywords: e-education, distance learning, COVID-19

DOI: https://doi.org/10.24818/beman/2021.S.I.2-01

\section{INTRODUCTION}

The context of COVID-19 got the world by surprise, a world that was not prepared to put a stop on the direct social interactions and to transfer it all to the wire. COVID-19 was declared a full pandemic at the beginning of 11th of March 2020 (Organization, n.d.) and since then the society tried to figure a way to continue in a context where they needed to limit contact to limit the spread. There were only a few systems that were able to continue fully working in an online environment.

Unfortunately, the educational system from Romania was not a lucky one. None of the "actors" implicated in this process were prepared for moving the work entirely online. In the case of primary school cycle there 
Radu, I.-M.

FIRST STRUGGLES OF THE EMERGING DISTANCE LEARNING NECESITY IN ROMANIAN EDUCATIONAL

SYSTEM IN THE CONTEXT OF COVID-19

were more challenges as the parents had to become the right hand of teachers and give more support than usual in the learning process.

The opinions, concerns and worries of the actors involved in the education of small children were shared over the internet to help each other understand better the different points of view.

This article aims to explore the feelings of the community the way they are published on platforms regarding the subject of continuing the work of education in an online environment. Centralizing similar opinions help the paper in underlining the frequent struggles that most of the people involved in teaching young students faced in the COVID-19 context.

\section{PROBLEM STATEMENT}

According to an EU report (Commission/EACEA/Eurydice, 2019), many EU countries are focusing on defining and developing digital skills at school. To achieve this scope, they included digital competencies as independent discipline or integrated them in the study of other disciplines.

The development of digital competencies involves also the access to digital resources. To be able to help with this, the Ministry of Education and Research from Romanian has funded the development of digital educational textbooks and the creation of resources able to fulfil the National Digital Agenda Strategy. (Digital Agenda for Romania 2020, n.d.)

Even though the preparation started, the COVID-19 put the Romanian educational system in the context where lots of struggles appeared. It was a time to figure out how the educational process can continue outside the classroom, how the teachers can help remotely and how the parents can support. The ones that were the most affected were the primary school children as they do not have the necessary skills to continue the learning process on their own or only with remote support.

\section{RESEARCH QUESTIONS}

The research questions that this study focuses on are: What are the struggles of the people involved in continuing the learning process at home for primary children? What are the challenges which the educational system in Romania has to overcome to deliver a more computer assister education as they are portrayed in the online news platforms?

\section{PURPOSE OF THE STUDY}

The purpose of this study is to portray the challenges of the people involved in the learning process of primary school children in the context of COVID-19 social distancing. It is important to understand how 
this sudden change has affected education. This will help in being able to come with solutions for the future. As we understand the importance of digital skills, it is clear the need for a smooth transition to a more computer-friendly environment and online processes. The process should learn to adapt to this situation and change according to the discoveries that emerged.

\section{RESEARCH METHODS}

For this study a qualitative method was used. To have a better overview of the social context, sites that offered interaction though comments regarding information about the steps that the education system had to take in the "\#stayathome" period were analysed. After looking on different platforms the most relevant one has proven to be Edupedu (https://www.edupedu.ro/, n.d.) and the Facebook page of the Romanian Ministry of Education and Research. Edupedu is a Romanian site for news regarding education. Every published article on the site has a comment section where readers can express their opinion in regards with the topic. For this study there were selected the opinions of the people on the news articles published on the side regarding the steps the teachers needed to follow in the Covid-19 context at the start of the pandemic. Here the parents and teachers found a safe place to express the struggles. Most of them were concentrated on the way the activities had moved and continued in an online environment.

From the Facebook page of the Romanian Ministry of Education and Research there were also selected the posts that were announcing relevant decisions to continuing the learning process online. The way Facebook it is structured, the posts encourage interactions through comments and reactions, so it felt like a safe place for people to express.

All the relevant comments from the two sources were gathered in a database and translated into English. This way a database of "emotions" was created. The opinions were put through a software which highlights the most frequent struggles and based on that some conclusions were drawn.

In Figure 01 the summary of "emotions" can be observed. This image was obtained by taking the database through the WordClouds software (Word Clouds, n.d.). The comments were inserted in the generator to obtain a word cloud. Word Clouds (also known as wordle, word collage or tag cloud) are visual representations of words that give greater prominence to words that appear more frequently. (Create Live Word Clouds, 2021). In this study this kind of approch is usefull as word cloud provides a graphical representation of the opinions, allowing a viewer to form a quick intuitive view (DePaolo \& Wilkinson, May/June 2014). This way the reactions expressed in the online media, help form a view of the important aspects of the comments around education topics at the start of the pandemic. How does this work? The software counts the encounters of words through the selected comments and draws the word by frequency: the most used ones are more emphasized. For a clear point of view linking words were taken out of the representation. 
Radu, I.-M.

FIRST STRUGGLES OF THE EMERGING DISTANCE LEARNING NECESITY IN ROMANIAN EDUCATIONAL

SYSTEM IN THE CONTEXT OF COVID-19

From Figure 1 it can be easily observed that the main actors that appeared in the comments were the teachers, the children, the parents. Other words that are highlighted like "know", "want", "time", "salaries", "internet" refers to the endeavours that the people engaged in the comment sections felt in relation to moving to online education. Everyone had uncertainties regarding how things will continue without having a clear knowledge of technologies, software, and even how the process will be. Furthermore, everyone wanted to continue their lives as before the start of the pandemic, but the time needed for the learning curve was also on everyone's thoughts. Salaries and internet are moving to the point of focus to the problem of the resources needed to a smooth transition to e-education.

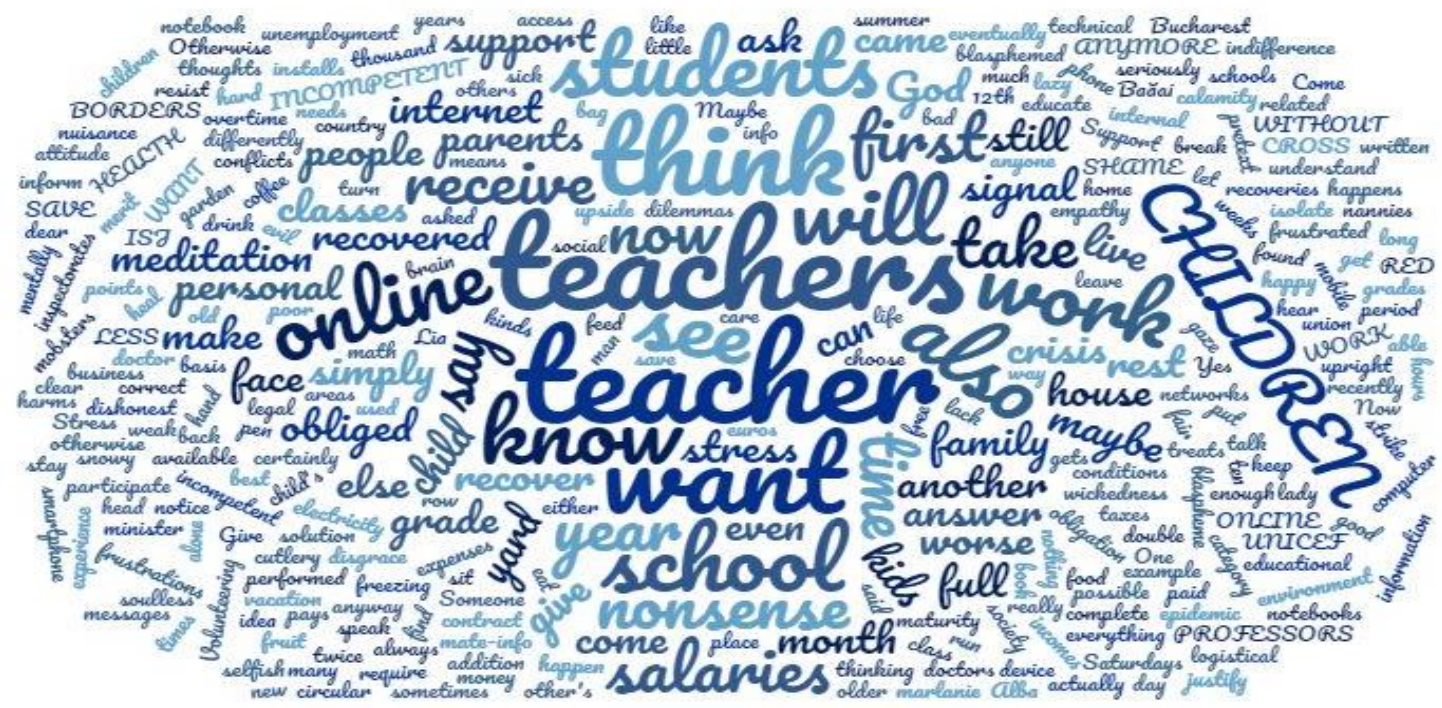

FIGURE 1: WORD CLOUD ANALYSIS OVER THE COMMENTS DATABASE

Source: Generated through the WordClouds software (Word Clouds, n.d.)

On a further assessment of the data when it comes to the main struggles $37,5 \%$ of the comments mentioned problems with the resources to continue the process online. No internet access, no devices, no electricity were some of the problems mentioned. When the focus changed on the teachers' opinions, $50 \%$ of them exposed that they or their pupils had struggles when it came to having the necessary resources to continue their learning process in an online manner. Taking into consideration the abilities needed to prepare the online lessons with everything that it implies from having knowledge of different technologies and software to use to how to keep the audience active in an online environment, more than $43 \%$ of the parents' comments analysed put an accent on the fact that the teachers did not had these kinds of skills. From the teachers' perspective, $32 \%$ of them have expressed their struggles with the skills needed for online learning, while $28 \%$ of them expressed their frustration 
with not having a universally agreed online education platform to use and clearly defined steps and procedure to follow.

\section{FINDINGS}

In social media people tend to be more vocal and express their feelings easier. The analysis of the comments relevant to the topic of distance learning in the context of COVID-19 created an image where the actors had opinions to share. Their point of view is important to understand as some solutions have to be found for the future. The actors' struggles that will be presented in the following paragraphs as they are portrayed in the analysed comments are the ones of the inspectors, the teachers and the parents. Even though the children are important actors, the elementary schoolers do not tend to express their opinions, at least not in the chosen comments for the study.

\subsection{The inspectors}

They were surprised and they could not force the teachers into distance learning because they did not prepare them for this. They also knew that at that point, at the start of social distancing, they did not have the resources needed for this. Because of all, they suggested that online learning is nice to have but not a must.

\subsection{The teachers}

Most of the teachers wanted to help the pupils but they did not have the right skills to use all kinds of platforms and neither the knowledge that they exist. If somehow they managed this, they had to fight with the problem of devices. Most of the pupils did not have computers, or if they had, the parents also needed to use them for work. To continue their lessons, they needed the help of the parents, which most of them were not prepared to work with the pupil from zero as a person with pedagogical skills is. So, considering all of the above, most of the teachers have gotten to the conclusion that having new lessons is really difficult in these times, so they mostly focus on consolidating what was already learned.

\subsection{The parents}

The parents also faced a new challenge: being a parent and a teacher helper, while trying also to continue working a job. The children needed the devices, devices which were kept away to reduce some of the bad effects they have on children. In some cases, the parents needed the devices for their work so sharing was hard. In the opinions some of them are accusing the teachers for not having a solution for their life to magically become as it was. 
Radu, I.-M.

FIRST STRUGGLES OF THE EMERGING DISTANCE LEARNING NECESITY IN ROMANIAN EDUCATIONAL

SYSTEM IN THE CONTEXT OF COVID-19

\section{CONCLUSIONS}

COVID-19 made all of us to think outside the box and find innovative solutions to new challenges. For the educational system in Romania this meant a lot of effort at the start of the pandemic for all the actors involved in the learning process. This made them want to share their opinions online to create a better overview of the situation and their impediments in continuing the learning process at home. The most affected were the primary school children who do not have the necessary skills to continue the learning process only with remote support.

The aim of this paper was to synthesize the first struggles the primary education faced in the context of COVID-19 as they are portrayed through the opinions of the actors on platforms related to education. These struggles can be used further to come with solutions for having a more digitalized educational system.

\section{ACKNOWLEDGEMENTS}

Parts of this paper have been presented at the online international conference Education, Reflection, Development (ERD 2020) 26-27 June 2020.

This paper was co-financed from the Human Capital Operational Program 2014-2020, project number POCU / 380/6/13/125245 no. 36482 / 23.05.2019 "Excellence in interdisciplinary PhD and post-PhD research, career alternatives through entrepreneurial initiative (EXCIA)", coordinator The Bucharest University of Economic Studies".

\section{REFERENCES}

Commission/EACEA/Eurydice, E. (2019). Digital Education at School in Europe. Eurydice. Luxembourg: Publications Office of the European Union.

Create Live Word Clouds. (2021, June 2021). Retrieved from Mentimeter: https://www.mentimeter.com/features/word-cloud

DePaolo, C. A., \& Wilkinson, K. (May/June 2014). Get Your Head into the Clouds: Using Word Clouds for Analyzing Qualitative Assessment Data. TechTrends, 58(3), 38-45.

Digital Agenda for Romania 2020. (n.d.). (Ministry of Communications and Information Society )

Retrieved March 4, 2006, from https://www.comunicatii.gov.ro/agenda-digitala-pentru-romania-2020/ https://www.edupedu.ro/. (n.d.). Retrieved Aprilie 2020, from https://www.edupedu.ro/ Organization, W. H. (n.d.). Listings of WHO's response to COVID-19. Retrieved February 4, 2021 Word Clouds. (n.d.). Retrieved April 15, 2020, from https://www.wordclouds.com/ 